\title{
ETIDOCAINE: AN EVALUATION IN EPIDURAL ANALGESIA FOR OBSTETRICS
}

\author{
P.R. Bromage, M.B., B.S., F.F.A.R.C.S., F.R.c.P.(c), S. DATTA, M.B., F.F.A.R.C.S., \\ and Lorna A. Dunford, s.R.N., R.S.C.N."
}

Etmocaine is a local anaesthetic with high lipid solubility and strong proteinbinding characteristics. Preliminary reports claim that the agent has a very rapid onset and a long duration of action. ${ }^{1}$ These characteristics should make the drug an attractive choice for epidural analgesia in obstetrics. Rapid onset is clearly desirable in a swiftly changing clinical situation, while long duration makes frequent reinjection unnecessary and reduces the total amount of drug required in protracted labours. In addition, strong protein-binding ensures low levels of free circulating drug and discourages placental transfer to the foetus. ${ }^{2}$ The potency of etidocaine is estimated to be approximately twice that of lidocaine. ${ }^{1}$ Observations of epidural dose-requirements in surgical patients, reported in the preceding paper, support this estimate quite closely. ${ }^{3}$

The present report concerns the performance of etidocaine hydrochloride in epidural analgesia for pain relief in labour and vaginal delivery, and for Caesarean section in a total of 110 patients.

\section{METHODS}

Continuous lumbar epidural blockade was performed in 110 obstetrical patients. Ninety-five patients received epidural analgesia for vaginal delivery using etidocaine 0.25 or 0.5 per cent, in plain solution or with epinephrine $1 / 200,000$. The remaining 15 patients received epidural block for Caesarean section using 1 per cent etidocaine with epinephrine (Table I).

Management of epidural analgesia and assessment of results were similar to those described in earlier communications. ${ }^{4,5}$ Analgesia was induced when labour was established and when the mother requested relief of pain. Puncture was performed at the second lumbar interspace, using the loss-of-resistance test, with the patient in the lateral position.

Dosage was chosen with a view to using the minimum amount of local anaesthetic for the task in hand, namely to ensure comfortable labour, painless episiotomy, delivery and perineal repair. Two-thirds of the induction dose were injected up the epidural needle prior to inserting the epidural catheter in a cephalad direction. The needle was then withdrawn and the catheter was taped in place. The patient was immediately turned onto the opposite side in order to encourage an even segmental spread, and the remaining one-third of the induction dose was injected up the catheter. Five minutes later the patient was turned

-Departments of Anaesthesia, Royal Victoria Hospital and McGill University, Montreal, Canada. 
TABLE I

Distribution of 110 Obstetrical Cases of Epidural Blockade with ETIDOCAINE

\begin{tabular}{llc}
\hline & \multicolumn{1}{c}{ Etidocaine solution } & $\mathrm{n}$ \\
\hline Caesarean section & $1 \%+$ epinephrine $1 / 200,000$ & 15 \\
Vaginal delivery & $0.5 \%$ + epinephrine $1 / 200,000$ & 25 \\
& $0.25 \%$ + epinephrine $1 / 200,000$ & 25 \\
& $0.5 \%$ plain solution & 25 \\
& $0.25 \%$ plain solution & 20 \\
\hline
\end{tabular}

on her back and the blood pressure was recorded at frequent intervals for 10 to 15 minutes. At any sign of arterial hypotension the patient was turned on her left side.

Cutaneous analgesia was tested with pin-prick, using a 22-gauge needle and a segment-time diagram was constructed in each case to show the upward and downward spread of analgesia, and to record any patchiness or "missed segments" that might have occurred., ${ }^{6,7}$ Motor block was assessed on the basis of voluntary movement in the legs, as described elsewhere. ${ }^{8}$ Ability to move knees and ankles freely was classed as "nil" ( 0 per cent), partial impairment of knee flexion as "partial" ( 33 per cent), inability to move the knees but free ankle movements as "almost complete" (66 per cent), no knee or ankle movements as "complete" (100 per cent). Just after delivery the mean score of the two legs was recorded as the score of the motor blockade.

Analgesic success was assessed in terms of comfort during the first and second stages of labour, and pain relief during delivery and perineal repair. For statistical comparison one of two possible sensory scores could be allotted in each case. Analgesia was scored as 100 per cent successful if the whole process of labour and delivery was conducted satisfactorily under epidural blockade alone, while a score of zero was given if supplementary analgesia or anaesthesia was required at any stage.

Maintenance or reinforcing epidural doses were given through the in-dwelling catheter when pain returned. The size of the maintenance dose was determined by the adequacy of segmental spread resulting from the original induction injection. Prior to delivery the patient was tested for analgesia to pin-prick in the lower sacral segments; if perineal analgesia was deficient the patient was placed in lithotomy stirrups and tilted head up, and a volume equivalent to twice the maintenance dose was injected up the catheter (Table II). Five minutes later the operating table was placed horizontal and the patient was prepared for delivery.

One per cent etidocaine with $1 / 200,000$ epinephrine was used for Caesarean section. The dose was chosen to provide analgesia of all segments up to a level between the fourth and sixth thoracic dermatomes. Age and, to a lesser extent, height were the two determinants in deciding upon the induction dose, which varied between $140 \mathrm{mg}$ and $225 \mathrm{mg}$ in this series. The selected volume was given as a single injection at the second lumbar interspace, in the sitting position, and an epidural catheter was then inserted. 
TABLE II

Induction Dose and Duration of Epidural Analgesia with Etidocaine in the First Stage of Labour

\begin{tabular}{llc}
\hline \hline Solution & $\begin{array}{c}\text { Average } \\
\text { Induction Dose } \\
(\mathrm{mg})\end{array}$ & $\begin{array}{c}\text { Average Duration } \\
\text { (minutes) }\end{array}$ \\
\hline $0.5 \%+$ epinephrine & $30(6 \mathrm{ml})$ & 99 \\
$0.25 \%+$ +epinephrine & $25-30(10-12 \mathrm{ml})$ & 80 \\
$0.5 \%$ plain & $30-40(6-8 \mathrm{ml})$ & 70 \\
$0.25 \%$ plain & $30-35(12-14 \mathrm{ml})$ & 55 \\
\hline
\end{tabular}

Patients for vaginal delivery received an intravenous infusion of one half to one litre of 5 per cent dextrose in water, Caesarean section patients received one litre of saline. In addition, 100 per cent oxygen was given by mask for 5 to 10 minutes prior to and during delivery. If maternal hypotension occurred at any time the mother was placed in the left lateral position. Caesarean section patients were placed supine with a sandbag under the right hip, to displace the uterus to the left and diminsh pressure on the inferior vena cava. Hypotension that did not respond to these measures was quickly corrected with an intravenous injection of $10 \mathrm{mg}$ ephedrine.

Blood concentrations of etidocaine were estimated in mother and foetus in 8 cases of Caesarean section. Maternal blood samples were taken from the umbilical vein and artery of a double-clamped section of cord. Etidocaine concentrations were measured by gas chromatography.

\section{RESULTS}

\section{Onset Time}

Initial onset of blockade was rapid, and cutaneous analgesia spread swiftly to its segmental limits. In the Caesarean section series 1 per cent etidocaine had an initial onset time of less than 4 minutes, and dermatome spread was complete in 10 to 15 minutes. It was usually possible to make the skin incision within eight minutes of injection. An equally rapid onset was found with the 0.5 per cent solutions used for vaginal delivery and a segmental block could be extended to embrace all the sacral and lumbar segments within 10 to 12 minutes of injecting the "perineal dose" prior to delivery.

\section{Dose Requirements}

In common with all other agents we have tested, segmental analgesia spread significantly further than in the non-pregnant population. ${ }^{9,10}$ Figure 1 shows the segmental dose-requirements (in terms of dose divided by the number of analgesic segments) for the 15 Caesarean section patients, compared with the mean for the normal surgical population. The mean dose-requirements for the pregnant population are about 28 per cent less than for the non-pregnant patients. Statistically, this difference is highly significant $(\mathrm{p}<0.001)$.

The total cumulative dose for each vaginal delivery was plotted against the total time of analgesia, from induction to completion of perineal repair after 


\section{1\% Etidocaine: Dose Requirements at Term}

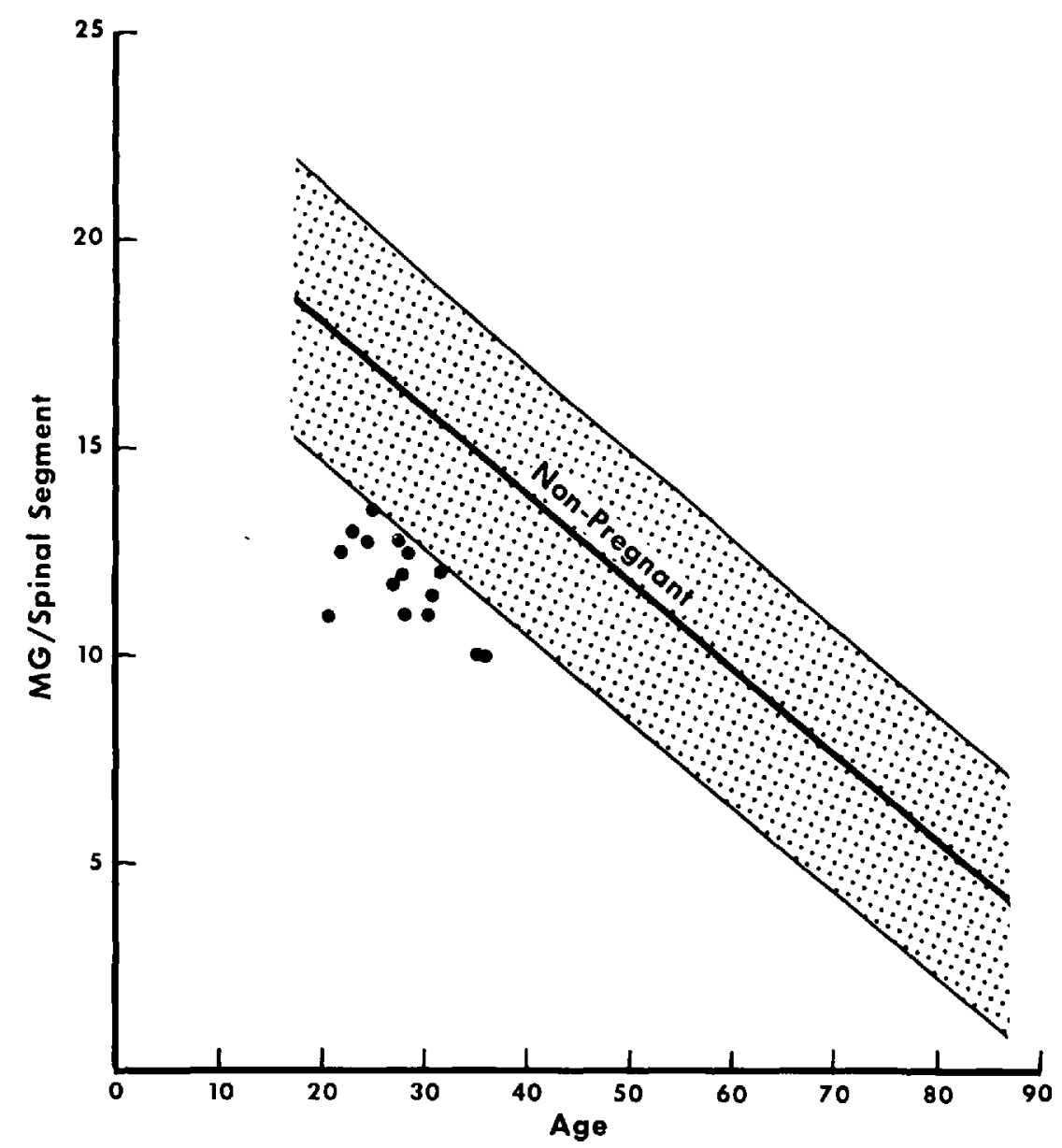

Frgure 1. Dose-requirements for 1 per cent etidocaine at term. Fifteen cases of Caesarean section compared to normal non-pregnant subjects. (Stippled area shows 95 per cent confdence limits of the normal population.)

delivery. This relationship is shown in Figure 2. Analgesic failures requiring supplementary anaesthesia are shown as crosses. It can be seen that the epinephrinecontaining solutions have smaller cumulative doses and lower failure rates than the plain solution without epinephrine.

No economy of dosage was achieved by using the 0.25 per cent solution and there is no significant difference between the cumulative dose-requirements of the 0.25 per cent and the 0.5 per cent solutions.

\section{Duration}

Etidocaine did not appear to have remarkably long-acting properties under the conditions of trial for vaginal delivery and maintenance injections had to be given at intervals of 50 to 90 minutes.

From Table II it can be seen that the duration of the 0.25 per cent and the 


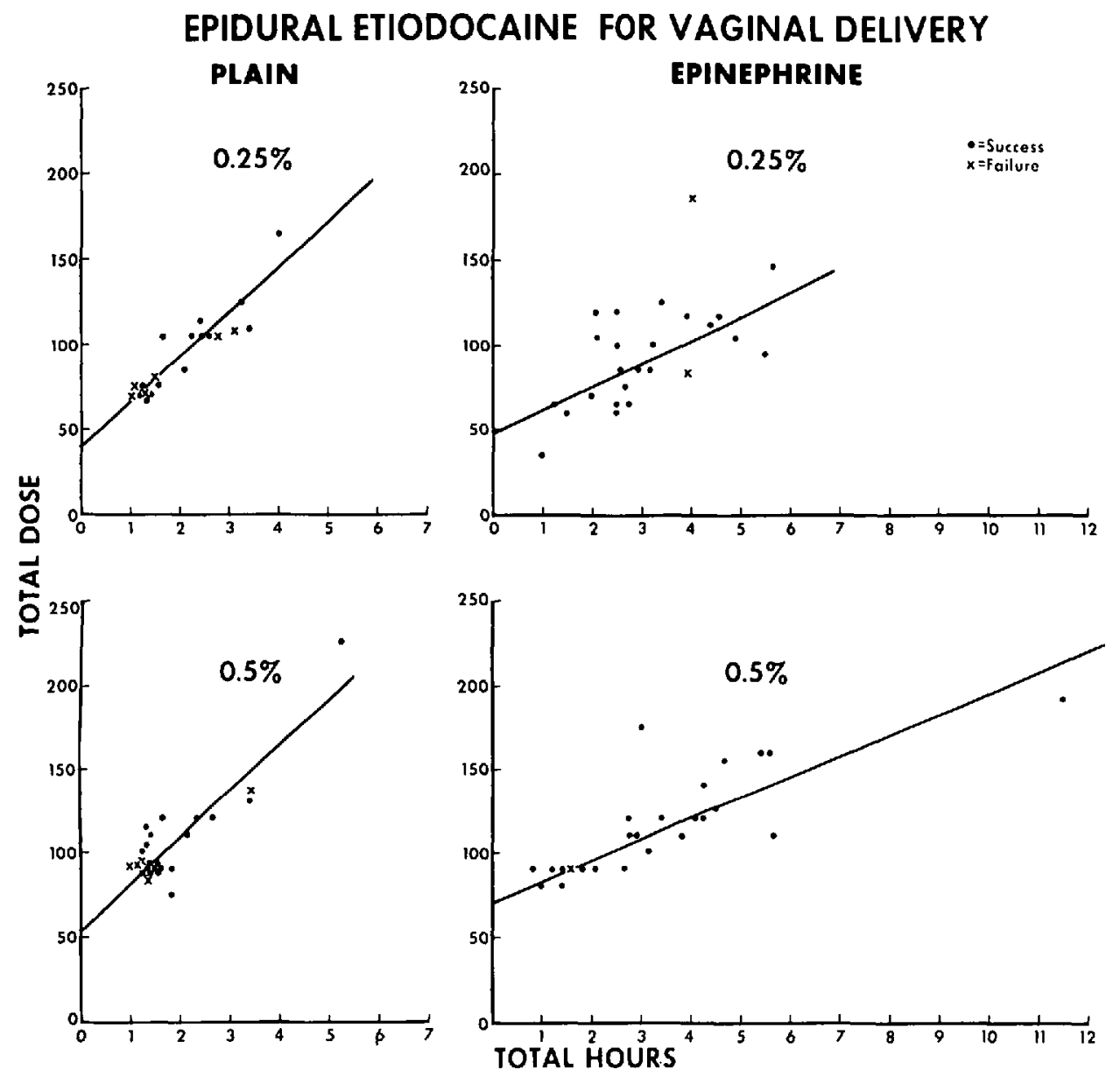

Figure 2. Cumulative dose-requirements of etidocaine for continuous epidural analgesia during labour and delivery.

$\mathrm{O}=$ Successful analgesia
Calculated regression lines drawn through data points.

0.5 per cent solutions was prolonged 30 to 40 per cent by the addition of epinephrine $1 / 200,000$.

\section{Quality of Sensory and Motor Blockade}

The quality of sensory analgesia with 1 per cent etidocaine and epinephrine was satisfactory for Caesarean section. However, most patients complained of lower abdominal soreness to some degree during the operation, and supplementary analgesia was required in 12 of the 15 patients after abdominal delivery.

The presence of epinephrine had a profound effect on the intensity of motor block and to a lesser extent on the intensity of sensory block. The quality of sensory blockade was satisfactory for vaginal delivery with 0.5 per cent etidocaine with epinephrine, but marginal or frankly unsatisfactory with the other solutions (see Table III and Figure 3). The 0.25 per cent concentration with 
TABLE III

Etidocaine in Obstetrical Analgesia: Influence of Concentration and Epinephrine $1 / 200,000$ on INTENSITY OF SENSORY and Motor Blockade aNd CuMUlative EpiduraL DOSE-REQUIREMENTS

\begin{tabular}{|c|c|c|c|c|c|c|c|c|}
\hline \multirow{2}{*}{$\begin{array}{l}\text { Etidocaine } \\
\text { Solution }\end{array}$} & \multirow[b]{2}{*}{$\mathbf{n}$} & \multirow{2}{*}{$\begin{array}{l}\text { Average } \\
\text { Sensory } \\
\text { Score }(\%)\end{array}$} & \multicolumn{4}{|c|}{$\begin{array}{l}\text { Degree of } \\
\text { Motor Block: } \\
\text { No. of legs in } \\
\text { each category }\end{array}$} & \multirow{2}{*}{$\begin{array}{c}\text { Average } \\
\text { Degree of } \\
\text { Motor Block }\end{array}$} & \multirow{2}{*}{$\begin{array}{c}\text { Average } \\
\text { Cumulative } \\
\text { Dose for } \\
5 \text { hours } \\
\text { Analgesia } \\
\text { (mg) }\end{array}$} \\
\hline & & & $\mathrm{N}$ & $\mathrm{P}$ & $A C$ & C & & \\
\hline $1.0 \%+$ epinephrine & 15 & 100 & - & - & 5 & 25 & 94.3 & - \\
\hline $0.5 \%+$ epinephrine & 25 & 96 & 2 & 4 & 24 & 20 & 74.3 & 135 \\
\hline $0.25 \%+$ epinephrine & 25 & 92 & - & $1 \overline{9}$ & 20 & 11 & 60.9 & 120 \\
\hline $0.5 \%$ plain & 25 & 80 & 12 & 27 & 9 & 2 & 31.7 & 192 \\
\hline $0.25 \%$ plain & 20 & 70 & 27 & 12 & 1 & - & 11.5 & 170 \\
\hline
\end{tabular}

epinephrine gave adequate relief of first stage pain, but relatively poor analgesia for the more stimulating events of episiotomy, delivery and perineal repair and there was a clinical failure rate of 8 per cent. The plain solutions were clinically inadequate with failure rates of 20 and 30 per cent for the 0.5 and 0.25 per cent concentrations respectively, and trial of the 0.25 per cent concentration was abandoned after 20 cases.

The phenomenon of "missed segments," where one or more dermatomes within the segmental field escape analgesia, was remarkably uncommon. There was an overall incidence of 5 per cent for partially missed segments and 2 per cent for completely missed segments. This incidence is considerably lower than one of us found for bupivacaine and lidocaine in an earlier series. ${ }^{7}$

Motor blockade was strangely intense compared to the marginally effective sensory analgesia. A marked degree of lower limb paresis was found with all the epinephrine-containing solutions but less motor block was encountered with the plain solutions. The relationship of motor blockade to sensory score is shown in Figure 3. One per cent etidocaine with epinephrine caused profound motor paralysis with complete immobility of the legs in most cases, and a motor score of 94 per cent. The 0.5 per cent concentration with epinephrine achieved a slightly lower motor score, with 80 per cent, while the 0.25 per cent solution with epinephrine gave 61 per cent motor block. With all these concentrations patients were unable to move themselves from bed to delivery table without assistance. Moreover, abdominal expulsive efforts were severely impaired whenever the upper level of segmental blockade rose higher than the tenth thoracic segment.

\section{Blood Concentrations and Placental Transfer}

Maternal and foetal blood samples were collected during eight Caesarean sections. The mean blood concentrations at birth were as follows: maternal venous $0.45 \mu \mathrm{g} / \mathrm{ml}$, umbilical vein $0.16 \mu \mathrm{g} / \mathrm{ml}$, and umbilical artery $0.08 \mu \mathrm{g} / \mathrm{ml}$.

The foetal heart rate was monitored by external counter in every case and there was no indication of distress secondary to epidural induction or mainte- 
BROMAGE, et al.: ETIDOCAINE FOR OBSTETRICS

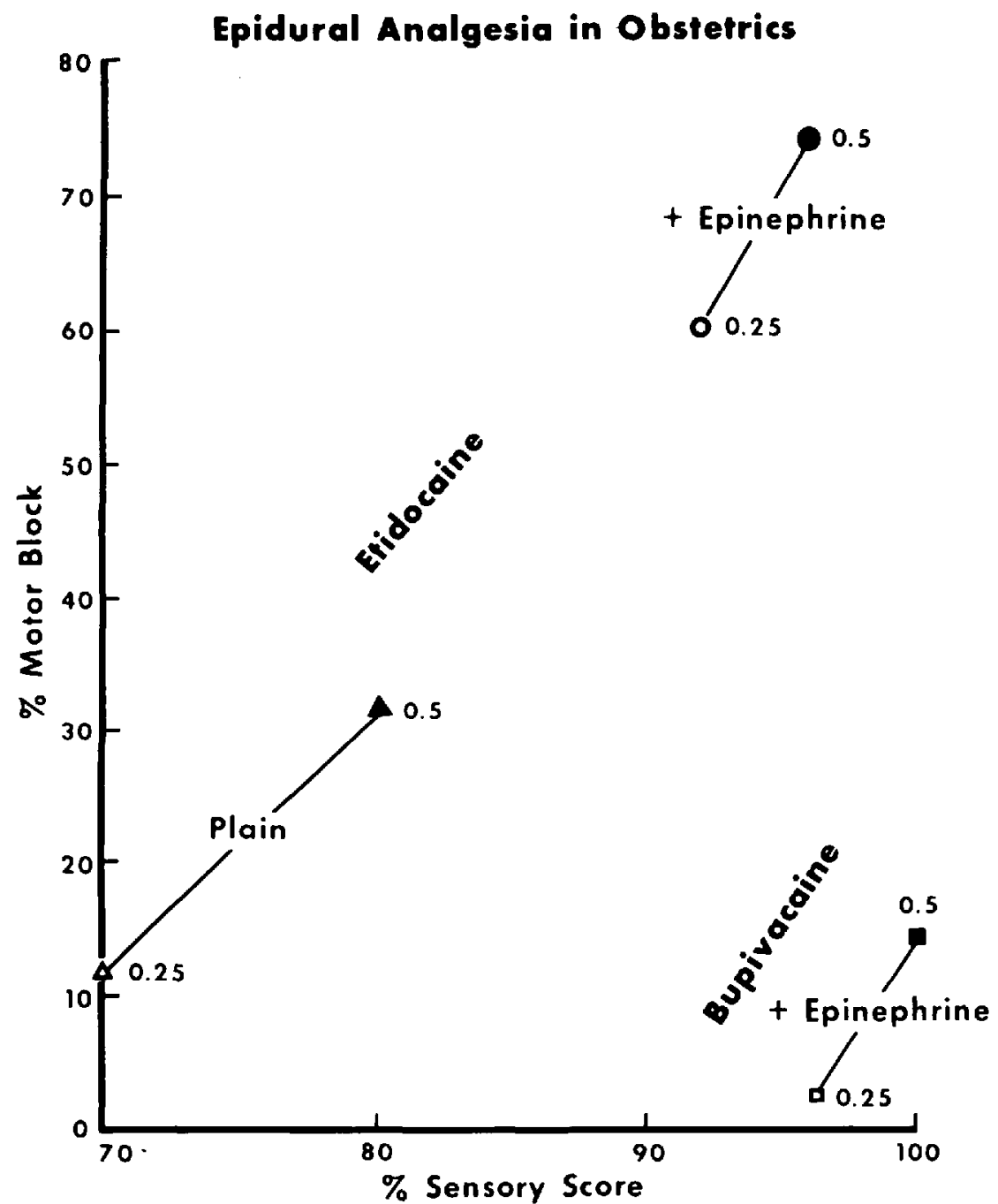

Figure 3. Dissociation of sensory and motor blockade. 0.25 and 0.5 per cent etidocaine, with and without epinephrine 1/200,000 compared to bupivacaine ${ }^{5}$ (see text).

nance, with the possible exception of one case described below. Foetal performance was good and babies were active at birth with an average one minute Apgar score of 8.5 (range 7 to 10 ). The average time from birth to sustained respiration (TSR) was 18 seconds for vaginal delivery and 29 seconds for Caesarean section.

\section{Toxicity}

Transient local discomfort or mild pain accompanied the induction dose in most cases. This was attributed to local irritation caused by the rather marked acidity of the solution ( $\mathrm{pH}=4.37$ plain, 3.92 with epinephrine).

One incident of acute toxicity occurred from inadvertent intravenous injection. With the exception of this one case, no other evidence of acute or chronic toxicity was encountered. 


\section{Case Repont}

Epidural analgesia was induced in a 32-year-old nulliparous patient with 8.0 $\mathrm{ml}$ of 0.25 per cent etidocaine with $1 / 200,000$ epinephrine. Cervical dilatation was $6 \mathrm{~cm}$. In this instance a departure was made from normal routine, and the full initial dose was injected up the needle. A catheter was then inserted. Induction of labour was induced with a syntocinon intravenous drip at a rate of about $10 \mathrm{mU} / \mathrm{min}$. One hour later the cervix was fully dilated and preparations were made to inject a perineal dose of $16 \mathrm{ml}$ of 0.25 per cent etidocaine (i.e. $40 \mathrm{mg}$ ) in the sitting position. Aspiration was performed and no blood appeared in the catheter. A pause was made after injecting $6 \mathrm{ml}$ of 0.25 per cent etidocaine with epinephrine (i.e. $15 \mathrm{mg}$ ). At this point the patient began to convulse violently and consciousness was lost. She was placed supine, intubated with a cuffed Portex tube and inflated with oxygen. Convulsions were arrested with diazepam $10 \mathrm{mg}$ intravenously. The blood pressure fell to about $60 \mathrm{~mm} \mathrm{Hg}$, and ephedrine $10 \mathrm{mg}$ was given intravenously. Resuscitation was eventually successful and a live baby was delivered by outlet forceps with a I-minute Apgar score of 7 . The epidural catheter was extracted and found to contain blood. Recovery was complete. An electroencephalogram three days later showed no evidence of spikeand-wave pattern. Skin wheal tests for drug sensitivity were negative.

It was concluded that the patient had suffered a toxic reaction to a bolus of $15 \mathrm{mg}$ of etidocaine injected into an extradural vein. The patient had not been receiving any other medication and the only other drug administered at the time was syntocinon at a rate of about $15 \mathrm{mU} / \mathrm{min}$.

\section{Discussion}

At term, pregnant women are more vulnerable and sensitive to epidural analgesia than the non-pregnant population and analgesic dose-requirements are reduced by about 25 to 30 per cent below normal. ${ }^{9,10}$ Observations of the quality and spread of epidural analgesia during labour and delivery can be made with considerable precision over a long period of time, while the intensity of motor blockade can also be assessed simply but quite precisely in terms of ability to move the legs, and to exert forceful expulsive efforts. This sensitive and yet physically active situation allows a more subtle discrimination of the sensory and motor aspects of epidural performance than in the relatively passive situation of the non-pregnant surgical patient.

The functional requirements of epidural analgesia in obstetrics are quite clear cut. Vaginal delivery with active participation by the mother demands a technique that provides good sensory analgesia of the lower abdomen and perineum, with minimal motor paralysis. On the other hand, abdominal delivery by Caesarean section requires both rapid and profound analgesia, together with satisfactory abdominal relaxation. Hence, a local anaesthetic that produces minimal motor blockade is good for vaginal delivery, but it is not necessarily suitable for Caesarean section. And while profound motor block is appropriate for Caesarean section, it is quite unacceptable for active matemal participation in vaginal delivery. 
Our results show that while etidocaine is a useful agent for abdominal section, it does not meet the functional requirements for active vaginal delivery. The intensity of motor block was extreme and surpassed that of all other agents we have tested, and paralysis was inappropriately severe compared with the quality of sensory analgesia. A similar dissociation between motor and sensory blockade has been found with epidural tetracaine which also gives marked motor paresis, but relatively poor sensory scores. ${ }^{5}$

This type of dissociated action with heavy motor paresis and relatively tenuous sensory analgesia should be contrasted with bupivacaine which provides clinically effective analgesia with minimal motor blockade. This contrast is shown graphically in Figure 3, where the sensory and motor qualities of etidocaine in this series are compared to the performance of bupivacaine under similar conditions of trial. ${ }^{5}$

The cause of the motor sensory dissociation that we have described is still speculative and difficult to explain in terms of action on afferent and efferent pathways outside the spinal cord. It is possible that highly lipophilic drugs such as etidocaine may be taken up preferentially by myelin and other extraneural coverings of the large motor and sensory fibres, but at the time of writing there is no evidence from in vitro studies of isolated nerves to support this idea. On the other hand, there is circumstantial evidence that the explanation may lie in neuraxial blockade after penetration of the cord, with regional differences in uptake by the various ascending and descending tracts. ${ }^{11}$

Both sensory and motor block were markedly increased when epinephrine was added to the epidural solutions, and the intensity of motor block was more than doubled. Duration of action was also increased. Induction doses lasted about 30 per cent longer when epinephrine $1 / 200,000$ was added (see Table II) and cumulative dose-requirements were also reduced by about 30 per cent (see Figure 2). These suggest that etidocaine in plain solution is rapidly removed from the site of injection by vascular uptake and that competition between vascular and neural uptake is strongly affected by local vasomotor tone.

Finally, comparative potency and toxicity must be considered. Epidural doserequirements provide a pragmatic index of the amount of drug needed to attain a measurable clinical effect in terms of segmental area of blockade.

In this series the segmental dose-requirements for etidocaine between the ages of 17 and 40 years were about one half the amount required for lidocaine under the same conditions. ${ }^{10}$ Hence, in this age range and under conditions of trial, etidocaine is approximately twice as potent as lidocaine and about half as potent as bupivacaine. ${ }^{5}$ The relative toxicity of etidocaine is more difficult to estimate in man, but animal data by others suggest that it is disproportionately high when administered intravenously. Adams et al. (1972) showed that etidocaine is half as toxic as bupivacaine when given subcutaneously in mice, but about equitoxic with bupivacaine and four times as toxic as lidocaine when given intravenously. ${ }^{12}$ Munson and his colleagues (1973) obtained comparable figures by intravenous infusion in rhesus monkeys: they found that etidocaine was 4.5 times as toxic as lidocaine in terms of seizure threshold..$^{13}$ Thus, available animal data points to a normal therapeutic ratio for etidocaine when injected extravascularly, but a lower 
therapeutic index when the drug is given intravenously. Our experience with a florid toxic reaction to a bolus of $15 \mathrm{mg}$ injected accidentally into an extradural vein supports the view that etidocaine is disproportionately toxic when administered intravenously.

Experience from our department and elsewhere suggests that accidental injections into the extradural veins of pregnant women may be more likely to produce toxic effects than at other sites and at other times. Our case is remarkable for the gross response to a very small intravenous bolus of etidocaine, and it is reminiscent of a similar accident reported by Ryan after a small dose of bupivacaine. ${ }^{14}$ In Ryan's case $40 \mathrm{mg}$ of plain bupivacaine were injected a few minutes after a test dose of $10 \mathrm{mg}$ during the first stage of labour: a seizure followed, but there was no cardiovascular collapse.

Agents with high lipid solubility may be expected to show heightened toxicity after rapid intravenous injection. Etidocaine has remarkably high lipid solubility and protein binding qualities, and sequestration in a very large distribution volume of fat and protein occurs after injection at extravascular sites. However, rapid intravenous injection will allow the drug to enter a relatively small blood distribution volume in proportionately higher concentration, with direct access to the central nervous system and avid uptake into neural elements. From a practical point of view one may say that etidocaine has a comparable therapeutic ratio to lidocaine and bupivacaine when injected extravascularly, but it will be about twice as toxic if accidentally injected directly into the vascular compartment. Thus, rigorous precautions should be taken against intravascular injection.

\section{SUMMARY}

The long-acting local anaesthetic etidocaine was tested for epidural analgesia in 110 obstetrical patients. One per cent etidocaine with epinephrine was given for Caesarean section and 0.5 and 0.25 per cent etidocaine, with and without epinephrine, were used for vaginal delivery. The intensity of motor and sensory block was markedly influenced by epinephrine, although duration of action was less affected. The outstanding clinical features of the agent were rapid onset and symmetrical spread of analgesia, associated with a profound degree of motor paresis. The 1.0 per cent concentration with epinephrine was satisfactory for Caesarean section. Excessive motor block makes the 0.5 per cent concentration with epinephrine impractical for the active management of labour, while the quality of analgesia provided by the 0.25 per cent concentration is barely adequate for clinical purposes. The therapeutic index for etidocaine in epidural analgesia appears to be lower than for lidocaine.

\section{RÉSUMÉ}

Nous avons employé l'Etidocaine, un agent anesthésique local à longue action, en injection péridurale chez 110 malades d'obstétrique.

On a utilisé la solution à 1 pour cent épinéphrine pour les opérations césariennes et celle à 0.5 et 0.25 avec ou sans épinéphrine pour les accouchements. 
La présence d'épinéphrine, influence notablement lintensité du blocage moteur et sensoriel sans avoir sur la durée du blocage une action aussi marquée.

Cet agent se caractérise de façon remarquable au point de vue clinique par sa rapidité d'action, la diffusion symétrique de l'analgésie qu'il provoque et par l'intensité de l'atteinte motrice. La solution à 1 pour cent additionnée d'épinéphrine est satisfaisante pour les opérations césariennes mais l'atteinte motrice excessive accompagnant l'utilisation de la solution à 0.5 pour cent avec épinéphrine rend son emploi aléatoire au cours du travail; quant à la solution à 0.25 pour cent, la qualité d'analgésie qu'on en obtient est tout juste suffisante pour les applications cliniques.

L'index thérapeutique de l'Etidocaïne en en analgésie péridurale (obstétricale) nous apparaît plus bas que celui de la Lidocaine.

\section{ACKNOWLEDGMENTS}

Thanks are due to Astra Chemicals Inc. for a grant in support of this study and for supplies of etidocaine. Dr. R. Fynes assisted with statistical processing of data.

Dr. N. Boyes, Astra Pharmaceutical Products Inc., Worcester, Mass., U.S.A., kindly provided facilities for estimation of blood concentrations of etidocaine.

\section{REFERENCES}

1. Lund, P.C., Cwik, J.C., \& Pagdanganan, R.T. Etidocaine - a new long-acting local anesthetic agent: a clinical evaluation. Anesth. \& Analg. 52: 482-493 (1973).

2. Tucker, G.T., Boyes, R.N., Brimenbaugh, P.O., \& MoOre, D.C. Binding of anilide type local anesthetics in human plasma. Relationship between binding, physicochemical properties and anesthetic activity. Anesthesiology 33: 287-303 (1970).

3. Bromage, P.R. \& O'BeiRn, P. Etidocaine: a clinical evaluation for regional analgesia in surgery. Canad. Anaesth. Soc. J. 21 : 523-534 (1974).

4. Bromage, P.R. Improved conduction blockade in surgery and obstetrics: carbonated local anaesthetics Canad. Med. Assoc. J. 97: 1377-1384 (1967).

5. Bromage, P.R. An evaluation of bupivacaine in epidural analgesia for obstetrics. Canad. Anaesth. Soc. J. 16: 46-56 (1969).

6. Ducrow, $M$. The occurrence of unblocked segments during continuous lumbar epidural analgesia for relief of pain in labour. Brit. J. Anaesth. 43: 1172-1174 (1971).

7. BRомage, P.R. Unblocked segments in epidural analgesia for relief of pain in labour. Brit. J. Anaesth. 44: 676-679 (1972).

8. Bromage, P.R. A comparison of the hydrochloride and carbon dioxide salts of lidocaine and prilocaine in epidural analgesia. Acta anaesth. scandinav. Suppl. 16: 55 (1965).

9. Bromage, P.R. Continuous lumbar epidural analgesia for obstetrics. Canad. Med. Assoc. J. 85: 1136 (1961).

10. Bromage, P.R. Spread of analgesic solutions in the epidural space and their site of action: a statistical study. Brit. J. Anaesth. 34: 161-178 (1962).

11. Bromage, P.R. Lower limb reflex changes in segmental epidural analgesia. Brit. J. Anaesth. Awaiting publication.

12. Adams, H.J., Kronberg, G.H., \& TAKman, B.G. Local anaesthetic activity and acute toxicity of $( \pm)-2-(\mathrm{N}$-ethylpropylamino)-2',6'butyroxylidide, a new long-acting agent. J. Pharm. Sci. 61: 1829-1831 (1972).

13. Munson, E.S., Tucker, W.K., \& Emmro, B.S. Etidocaine and lidocaine induced seizures in Rhesus monkeys. Abstr. A.S.A. Annual Meeting, San Francisco 1973, p 173.

14. RyAN, D.W. Accidental intravenous injection of bupivacaine: complication of obstetrical epidural anaesthesia. Brit. J. Anaesth. 45: 907-908 (1973). 